\title{
The Clinic is The Curriculum: Can Attention to the Clinical Learning Environment Enhance Improvement in Health Care Delivery and Outcomes?
}

\author{
Elizabeth G. Baxley, MD
}

Actualization of knowledge and skills learned in medical education is required for medical students and residents to adopt effective clinical patterns and behaviors into their lives as practicing physicians. In addition, the imprinting of clinical behaviors that these trainees incorporate from the observations they make in the clinical learning environment in which they train has been well established to have a substantial and long-lasting impact on their approaches to care in subsequent practice settings. While much attention is paid to the formal curriculum for students and residents, supported by the need to meet requirements for accreditation, it is less common to witness explicit discussions and planning about the role that the clinical learning environment plays in the ultimate outcomes of educational efforts.

Despite being 3 decades into a national focus on the need to improve patient safety and quality of care delivered in the United States, substantive progress toward meeting Quadruple Aim goals remains elusive. In this commentary, the impact of the clinical learning environment on the production of graduates who are both knowledgeable about health system science competencies and incorporate them into the ways in which they view themselves and their work is posited to be one of the reasons contributing to the lack of consistent application of effective approaches to improving care. Recommendations for further training of faculty, alongside residents and students, are explored. Finally, models of medical education and curriculum must make the clinical learning environment "visible" in their planning, lest the outcomes they desire, and the nation needs, may never come to fruition. ( $\mathrm{J}$ Am Board Fam Med 2020;33:S46-S49.)

Keywords: Accreditation, Curriculum, Faculty, Goals, Learning, Medical Education, Medical Students, Patient Safety, Quality of Health Care

"Children learn what they live."

In 1955, a poem by this name was written by Dorothy Law Nolte. In it, she recognizes that the greatest influence that a parent can have on their children is the example that they set in their everyday lives. ${ }^{1}$ In many respects, the tenets of

This article was externally peer reviewed.

Submitted 9 December 2019; revised 14 May 2020; accepted 19 May 2020.

Funding: None.

Conflict of interest: The author is an employee of the ABFM.

Corresponding author: Elizabeth G. Baxley, MD, Executive Vice President, American Board of Family Medicine, 1648 McGrathiana parkway, Lexington, KY 40516 (E-mail: EBaxley@theabfm.org). organizational culture represent a parallel to Children Learn What They Live, for adults, in how they describe underlying beliefs, assumptions, values and ways of interacting within our workplaces. These often "hidden" components of an organization contribute to the unique social and psychological milieu in which people learn what is right or wrong, accepted or not accepted, behavior.

The practice of medicine is not simply a knowledge economy that is solely dependent on accessibility to a sufficient volume of high-quality information. For knowledge to have any impact it must be shared, or distributed, to patients and learners. Didactic learning-from medical school through residency 
and continuing medical education-must subsequently become actualized and reinforced in a clinical setting-and then observed by medical students or residents - for it to become an ingrained part of what they learn. When newly learned knowledge and skills are supported by what we observe in others and through positive reinforcement of our own actions, hardwiring of behavior occurs. Conversely, if what is learned in the classroom is not supported, or even contradicted, in our observations of the ways in which people behave in the clinical setting, that learning is often extinguished and replaced with mirroring what we observe.

But how does this relate to improving the quality of care we provide? Does the environment in which we train and work have any impact on the outcomes and experience of the patients we serve? A landmark study by McGlynn and colleagues ${ }^{2}$ in 2003 demonstrated significant gaps in acute, chronic, and preventive care in primary care settings when compared with guideline-based management. Their work highlighted the fact that we have not seen systematic, sustained improvements in reducing unwarranted variation in care delivery since this original study was published. Does this mean that we have simply failed to ensure that our learners and colleagues had access to up-to-date, evidencebased information to support their medical decision making? Of course not. Access to curated knowledge is more prevalent and easily accessible today than it was in 2003. Given the immense attention paid to patient safety and quality improvement over the past 2 decades, why haven't we seen greater improvements in care, more broadly applied across all geographies and populations? One only needs to look as far as the traditional paradigm of medical education and continuous professional development, which have emphasized knowledge acquisition and retention, to see that what is missing are specific skills of quality improvement and potentially the attitude that it is important to improve measured quality. To address this effectively, medical educators must acknowledge the impact and importance of the clinical learning environment on the behaviors of the next generation of physicians.

In 2008 a fourth-year student said to me, "Medical school has taught me a lot about the cardiovascular system ... the renal system ... and the pulmonary system. But soon I am going to graduate and will be working in a bealth care system-when do I get to learn about the system in which I will spend my time caring for patients?" Over time, more attention has been paid to the practice-based learning and improvement and systems-based practice core competencies originally described in 2002 by the Accreditation Council for Graduate Medical Education. The Institute for Health care Improvement developed its Open School, which has provided a globally accessed curriculum and supported a learning community of health professions students focused on patient safety and quality improvement. ${ }^{3}$ The National Board of Medical Examiners created a Health System Science examination to help medical educators and students assess their knowledge in these competencies. ${ }^{4}$ Most medical training today includes curriculum in competencies needed to improve health care systems: safety science, systems assessment and change, teamwork and communication, care transitions, and population health. With subsequent national initiatives like the American Medical Association's Accelerating Change in Medical Education Consortium, medical educators are gaining a common language around health systems science and seeing emergence of effective ways to build this into curricula across the spectrum from undergraduate medical education to graduate medical education. ${ }^{5,6}$ Even with all this, we are not that much closer to realizing the Quadruple Aim.

Was creating curriculum in health system science sufficient? No, because our learners are not consistently observing that which they are taught translated into the daily practices of health care professionals in the clinical learning environments in which they train! Consequently, they are learning what they live and failing to hardwire learned concepts into their own behaviors. Take interprofessional practice as an example. Students and residents now spend time in medical simulation with myriad other health professions students or practitioners. They certainly learn from those interactions. But what happens when they go into an actual clinical setting? They do not always see interprofessional practice emulated among those on whom they rely for their own identity formation. What happens? They leave their training practicing what they lived - the informal, or hidden, curriculum of the clinical learning environment. This is the critical curriculum that demands more of our attention if we want to truly improve care into the future.

Imprinting on observed and patterned behaviors they experience in the clinical learning environment has a powerful impact on learners that extends long 
after formal training is completed. Studies show that residents who train in high-cost clinical settings will continue those patterns of delivering high cost care, regardless of where they end up in practice, even if they move across the country, or subsequently work in a low-cost setting. ${ }^{7,8}$ Imprinting also impacts quality of care. In the OB/GYN literature, rates of surgical outcomes and complications that trainees experience during training continued to "follow" residents into their practices regardless of the setting or location. ${ }^{9}$ A study of 22 family medicine residency programs in the Southeast showed substantial variation across in quality, cost, and patient experience. ${ }^{10}$ And, this phenomenon seems to begin early in medical education, at the level of the medical student. A multi-center study of medical students showed that students learning in higher-health-care-intensity regions reported observing significantly fewer cost-conscious rolemodeling behaviors. ${ }^{11}$ In some of these settings, students said things like, "We're encouraged to present a broad differential with a big workup as proof that we are making the grade. That we're the better student."

In 2016, Brian Wong and Eric Holmboe ${ }^{12}$ published an article that shown light on the dichotomy we have had as medical educators. When we think about our role as teachers and evaluators of students and residents, we focus on measuring educational outcomes, centered around each learner. Have they met their Entrustable Professional Activities (EPAs)? Have they passed their United States Medical License Examination (USMLE) exams? What are their scores? Have they gotten in the right training programs when they finish? Do our graduates pass their board certification exams? In contrast, when we turn our minds to our work as clinicians we think about, and measure, clinical outcomes, centered around patients. Yet, from its inception, the ultimate role of formal medical education has been to improve care. What Wong and Humble describe as missing in our traditional model of medical education is the role and the influence of the clinical learning environment.

Rarely does attention to the clinical learning environment seem explicitly in the formal curricula of medical education programs. Yet, it is operating in the background as a key influencer of current and future behavior whether, we choose to acknowledge it or not. What is keeping us from integrating these 2 concepts of educational outcomes and clinical outcomes? Why are we not intentionally working to align the clinical learning environment with the competencies we are teaching? The answer is multi-factorial, but a major limiting factor is that we currently have an entire generation of faculty who themselves were not trained about patient safety, quality improvement, interprofessional practice, health equity, population health. How can we expect today's teachers to learn this and become change agents of the clinical learning environment when their days are spent teaching clinical medicine, while also providing direct patient care in complex and demanding environments, with little time for professional development and greater emphasis on focusing on their own well-being? ${ }^{13}$

To change this, there must be an institutional understanding of the far-reaching impact of the clinical learning environment, coupled with a commitment to provide meaningful professional development that is reinforced by real-life experience for faculty to apply this new knowledge in the clinical microsystems in which they work to make significant changes in our health care systems. ${ }^{14}$ In addition, sacred cows of medical training-such as traditional rotational models, lack of geographic clustering of patients with a consistent team, and more-need to be examined and replaced by new curricular structures to support active learning that "makes visible" to medical learners that there are more effective ways of delivering and improving care. If successful, the imprinting they experience has the chance to reinforce what principles have been taught in the classroom, thus creating the potential for exponential impact on their future behaviors and on clinical outcomes. And, finally, faculty must become comfortable with not always being the expert, but rather be willing to learn alongside, and with, their learners on that journey. Learners provide value-added contributions to both the educational and clinical environments, if we allow them — and they can help us meet the Quadruple Aim goals.

The 24 specialty certifying boards that comprise the American Board of Medical Specialties share a critical standard setting role in medical education. Is it time for us to insist that the clinical learning environment become part of the standards by which residency programs will be evaluated? Can we begin to acknowledge the need to evaluate a mix of educational and clinical outcomes? In both medical education and continuous certification, are we ready to support the use of more formalized workplace-based assessment to evaluate broad-based clinical competency? Finally, will American Board 
of Medical Specialties (ABMS) continue to promote a standard of requiring visible evidence of improving care in practice that fosters meaningful selfassessment and systems improvement as part of board certification. Without these, how else would we make progress in transforming the clinical learning environment to be 1 that models high quality, high value care that is both satisfying to patients and supports the health of its workforce?

To see this article online, please go to: bttp://jabfm.org/content/ 33/Supplement/S46.full.

\section{References}

1. Children Learn What They Live. 1954. Available from: https://childrenlearnwhattheylive.com. Accessed December 8, 2019.

2. McGlynn EA, Asch SM, Adams J, et al. The quality of health care delivered to adults in the United States. N Engl J Med 2003;348:2635-45.

3. Institute for Healthcare Improvement Open School. 2020. Available from: www.ihi.org/education/ ihiopenschool. Accessed December 8, 2019.

4. National Board of Medical Examiners. August 29, 2019. Available from: https://www.nbme.org/news/ new-health-systems-science-hss-examination-nowavailable-all-medical-schools. Published. Accessed May 13, 2020.

5. AMA Accelerating Change in Medical Education. June 2013. Available from https://www.ama-assn. org/education/accelerating-change-medical-education. Accessed December 8, 2019.

6. Gonzalo JD, Baxley E, Borkan J, et al. Priority areas and potential solutions for successful integration and sustainment of health systems science in graduate medical education. Acad Med 2017; 92:63-9.

7. Phillips RL, Petterson SM, Bazemore AW, Wingrove P, Puffer JC. The effects of training institution practice costs, quality and other characteristics on future practice. Ann Fam Med 2017;15: 140-8.

8. Chen C, Petterson S, Phillips R, Bazemore A, Mullan F. Spending patterns in region of residency training and subsequent expenditures for care provided by practicing physicians for Medicare beneficiaries. JAMA 2014;312:2385-93.

9. Asch DA, Nicholson S, Srinivas SK, Herrin J, Epstein AJ. How do you deliver a good obstetrician? Outcome-based evaluation of medical education. Acad Med 2014;89:24-6.

10. Page CP, Reid A, Drostin C, Newton WP. Variation in Triple Aim measures: implications of clinical signatures in family medicine residency programs. J Grad Med Educ 2018;10:548-52.

11. Leep Hunderfund AN, Dyrbye LN, Starr SR, et al. Attitudes toward cost-conscious care among U.S. physicians and medical students: analysis of national cross-sectional survey data by age and stage of training. BMC Med Educ 2018;18:275.

12. Wong BM, Holmboe ES. Transforming the academic faculty perspective in graduate medical education to better align educational and clinical outcomes. Acad Med 2016;91:473-9.

13. Clay MA, Sikon AL, Lypson ML, et al. Teaching while learning while practicing: reframing faculty development for the patient centered medical home. Acad Med 2013;88:1215-9.

14. Baxley EG, Lawson L, Garrison HG, et al. The Teachers of Quality Academy: a novel approach for preparing faculty to teach health system science. Acad Med 2016;91:1655-60. 